\title{
Som na forma tipográfica: a tipografia como recurso de imersão audiovisual para pessoas surdas.
}

\author{
Sound of typographic form: typography as an audiovisual immersion resource for the \\ deaf.
}

NORMANDI, Diego; Doutorando; USP | diegonmd@usp.br

TARALLI, Cibele; Doutora; USP | cibelet@usp.br

\begin{abstract}
Resumo
A legendagem de filmes é um recurso de acessibilidade dos mais antigos utilizados. Seu estudo se inclui no campo de pesquisa da Tradução Audiovisual, no qual uma série de características nas legendas são avaliadas e propostas. Uma lacuna identificada nesses estudos, no Brasil, se refere à exploração da tipografia como elemento informacional que extrapola a mensagem verbal. Este artigo, que integra pesquisa de Doutorado em Design, sobre inclusão de pessoas com deficiência no cinema, vem propor uma abordagem experimental, a partir de proposta piloto, na utilização do estilo tipográfico como recurso para ampliar a imersão do espectador surdo no universo audiovisual. Tomando como partido quatro pressupostos, o experimento foi aplicado em ciclos, envolvendo pessoas ouvintes e surdas em diferentes etapas e a partir de mecanismos de coleta de dados, realizados com e sem a presença do pesquisador. Os resultados aqui apresentados podem orientar o prosseguimento e aprofundamento de estudos com esta abordagem tanto no campo do Design e da Tipografia quanto da Tradução Audiovisual Acessível, sempre com a participação de usuários surdos.
\end{abstract}

Palavras Chave: Tipografia; tradução audiovisual acessível; legendagem para surdos e ensurdecidos; inclusão.

\begin{abstract}
Film subtitling is an accessibility feature of the older in use. His study is included in the field of Audiovisual Translation research, in which a series of characteristics in the subtitles are evaluated and proposed. A gap identified in these studies in Brazil refers to the exploitation of typography as an informational element that goes beyond the verbal message. This article, which integrates a Doctorate in $\mathrm{PhD}$ research, on the inclusion of people with disabilities in the cinema, proposes an experimental approach, from a pilot project, for application to the typographic style as a resource to expand the immersion of the deaf spectator in the audiovisual universe. Based on four assumptions, the experiment was applied in cycles, involving hearing and deaf people in different stages, realized with and without the presence of the researcher. The results presented in this paper should guide the continuation and deepening of studies with this approach in the field of Design and Typography as well as Audiovisual Translation, always with the participation of deaf users.
\end{abstract}

Keywords: Typography; accessible audiovisual translation; subtitling for the deaf; inclusion. 


\section{Introdução}

A legendagem consiste em recurso acessível dos mais populares no universo audiovisual. É possível afirmar que qualquer espectador alfabetizado, que mantém ou já tenha mantido alguma assiduidade nas salas de cinema, tenha utilizado tal recurso para compreender de forma integral os filmes exibidos, sobretudo os de língua estrangeira.

Quando se fala em acessibilidade, é comum relacionar o termo à condição de propor acesso a pessoas com deficiência. Entretanto, a Acessibilidade não deve ser resumida a este entendimento, especialmente quando a colocamos no contexto do Design. Neste trabalho, quando nos referimos a tal propósito, estamos considerando a necessidade de proporcionar acesso de pessoas em geral. Uma porta com medidas adequadas à passagem de humanos, com dispositivos de abertura e manuseio apropriados pode ser entendida como uma ferramenta acessível, uma vez que sem tal recurso, dois ambientes, mesmo que vizinhos, podem ter acesso inviabilizado. Nesta perspectiva, estamos compreendendo a legendagem como meio eficiente para ampliar o acesso de espectadores ao conteúdo de produtos audiovisuais.

Em termos práticos, a legendagem pode ser entendida como a exibição, via forma textual, de diálogos e informações escritas, com relevância informacional, em produtos audiovisuais. Sua utilização, no geral, se recomenda para suportar a tradução de materiais em língua estrangeira. Entretanto, também é indicada como tecnologia assistiva para inclusão de pessoas com deficiência auditiva ou cognitiva, com fins de ampliar a capacidade de imersão e compreensão destes sujeitos à respeito de conteúdos audiovisuais nos quais os recursos de imagens possam ser considerados insuficientes para apropriação das mensagens. Nesse sentido, o que dá suporte à legendagem são os caracteres tipográficos, que são responsáveis pela composição dos textos que surgem na tela. No universo das pesquisas em legendagem, se encontram diversos conteúdos que abordam a formatação dos textos, sobretudo quanto ao número de caracteres, a velocidade de leitura sugerida, a quantidade de linhas a cada passagem de legenda, entre outros parâmetros. Entretanto, o estilo tipográfico, como recurso semântico visual e entendido, para além da sua "invisibilidade" em textos de legendas em conteúdo audiovisual, parece não ter despertado o interesse científico do campo da Tradução nem do Design e da Tipografia.

\section{Contextualização}

Desde o início do cinema, a familiaridade entre espectador e conteúdo fílmico se fez necessária para imersão e compreensão da mensagem cinematográfica. Histórias narram o fato de que em uma das primeiras exibições de cinema, a plateia fugiu do ambiente ao ver uma locomotiva aproximar-se na tela de exibição. É de se supor que - caso o fato seja verídico - os que tenham fugido o fizeram pelo conhecimento anterior sobre o que representava aquele veículo, tendo sido impulsionados apenas pelo sentido da visão, uma vez que à época não havia a sincronização de áudio nos filmes.

No período do cinema mudo, as cenas eram acompanhadas, e porque não dizer interpretadas por uma trilha sonora, que muitas vezes era realizada ao vivo por uma orquestra. A música era responsável por transmitir as sensações e os sentimentos pensados pelos autores das produções cinematográficas. Muitas vezes, em vistas a completar a mensagem fílmica, as cenas eram intercaladas por telas com textos escritos, que expressavam falas dos personagens, indicações 
de passagem de tempo, localizações, entre outras necessidades informacionais. Nestes casos, a escolha tipográfica para tais soluções visuais não eram aleatórias e tinham objetivo claro de conduzir o espectador a uma compreensão da mensagem que ultrapassava a informação verbal, percorrendo também as características formais dos tipos utilizados. Claro que a partir de um olhar atual, sem contextualização gráfica e tecnológica suficiente, é possível desconsiderar a diversidade dos estilos tipográficos utilizados àquela época, uma vez que o uso de qualquer um daqueles modelos em uma peça visual atual, automaticamente faria referência àquele período, sem distinção clara de especificidades formais, já que o universo tipográfico disponível hoje nos permite essa redução semântica. Da mesma forma, a percepção das minúcias do estilo tipográfico é característica daqueles que se debruçam sobre o tema, haja vista que tais pesquisadores se especializam no melhor manejo das características formais dos tipos para a transmissão de mensagens visuais. No entanto, se pode crer que é possível que um indivíduo que não se dedica a esse tipo de conhecimento seja passível da influência do estilo tipográfico. Tal ideia é a primeira das pressuposições ${ }^{1}$ que compõem este artigo.

\section{Pressuposto 1}

A utilização de estilo tipográfico com características formais (e linguagem) particulares pode influenciar na percepção de conteúdo, que vai além do texto escrito.

\section{Pressuposto 2}

O indivíduo surdo pode encontrar na visão seu principal canal de comunicação com outros sujeitos, o que chama atenção para a possibilidade de se investir neste recurso para a aquisição de informação.

\section{Pressuposto 3}

Tanto o sujeito ouvinte quanto o surdo podem dispôr de percepção visual semelhante na compreensão das formas.

\section{Pressuposto 4}

O estilo tipográfico pode contribuir com a expansão da compreensão dos surdos quanto à mensagem audiovisual, seja em filmes, videoclipes, propagandas, games, entre outros.

\subsection{O Estilo tipográfico}

Para Ellen Lupton (2015, p.9), "a tipografia incorpora a linguagem escrita de uma forma concreta. Uma fonte comunica através de seus traços, proporções e peso visual". São essas características que identificam e classificam os tipos, ao mesmo tempo que transmitem sensações aos que interagem com eles. Diversos autores se dedicaram à atividade de classificar os estilos tipográficos, a partir da identificação de elementos comuns. Neste trabalho, não iremos nos dedicar a pontuar toda essa gama de possibilidades, entretanto podemos citar pelo menos três importantes obras que se debruçaram sobre o assunto, tais como Elementos do Estilo Tipográfico (BRINGURST, 2005), Pensar com Tipos (LUPTON, 2006) e, no Brasil, Estudos sobre Tipografia (FARIAS, 2016).

\footnotetext{
${ }^{1}$ Ressalta-se que em todos os pressupostos apresentados, se considera abarcar a diversidade de repertorio, de contexto cultural, e os diferentes níveis de percepção e conhecimentos dos sujeitos envolvidos (surdos ou não).
} 
Baines \& Haslam (2005) afirmam que a tipografia é intrinsecamente linguagem visual. Ao se considerar, por exemplo, a tipografia como uma espécie de roupa que "veste" um texto, é possível compreender o estilo tipográfico como um instrumento de comunicação que carrega mensagem particular na própria forma visual. Assim, um único texto poderia assumir diferentes relações a depender da tipografia que assume.

Quando se trata de tipografia aplicada à leitura fluida, tal como a experiência de ler um livro de muitas páginas, um jornal diário ou a legendagem de um filme, se pode considerar que, por padrão, é indicado a seleção de estilos que se tornem "invisíveis", no sentido de que a fonte sirva de ferramenta para facilitação da leitura e não assuma papel de protagonista no espaço. Frutiger (2007) traz a ideia de que as fontes não devem ser percebidas nesses contextos. Reforçando tal compreensão, Bringhurst (2005) diz que se o tipo é mal escolhido, as letras podem acabar interferindo no entendimento do conteúdo verbal que carregam.

É possível identificar a estratégia do uso de diferentes estilos tipográficos no universo das Histórias em Quadrinhos (HQ), haja vista que muitas vezes a utilização de tipos diferentes é proposta para a composição de mensagens que se propõem sonoras, como, por exemplo, as onomatopeias. Nesse sentido, em produções audiovisuais, mesmo as que contam com recurso de sincronização de som, já se valeram deste recurso de comunicação. Um exemplo é o seriado estadunidense Batman (que ficou conhecido no Brasil como Batman e Robin), produzido na década de 60. Neste programa, uma série de onomatopeias relacionadas, sobretudo, a sons de impactos ${ }^{2}$ foram representadas visualmente com o auxílio de diferentes estilos tipográficos.

\subsection{Legendagem}

Como já mencionado, a legendagem é um recurso de acessibilidade. Contudo, quando voltada à inclusão de pessoas surdas, a ferramenta tem método de desenvolvimento específico, uma vez que se considera que o entendimento da língua portuguesa escrita é diferente dentre aqueles que contam com o sentido da audição e aqueles que nasceram sem tal condição.

A legendagem orientada a pessoas ouvintes pode ser considerada como recurso de tradução, com métodos descritos por pesquisadores do campo da Tradução Audiovisual (D’Ydewalle et al, 1987; Ivarsson \& Carol, 1998; Díaz Cintas \& Remael, 2007; Neves, 2007 apud Araújo \& Nascimento, 2011). Já, quando voltada a surdos, pode ser entendida como instrumento de transcrição de fala e sons essenciais à compreensão da mensagem audiovisual (uma batida na porta, que faz os personagens dirigirem-na o olhar, por exemplo).

Lançado recentemente, o Guia para Produções Audiovisuais Acessíveis (2016) traz uma série parâmetros a serem seguidos para que se proponha conteúdos audiovisuais acessíveis. O guia é fruto do trabalho de grupos de pesquisa distribuídos pelo Brasil, concentrados no estudo da Tradução Audiovisual. No capítulo dedicado a legendagem são apresentadas as orientações pertinentes à construção de legendas:

\footnotetext{
${ }^{2}$ Alguns exemplos são Kapow, Crunsh, Whaack, Clunk, entre outros. Neste link, é possível verificar tal recurso: https://goo.gl/AxS9AF YOUTUBE. Batman (1966): Fight Scenes-Season 3 (Pt.2). Disponível em: <https://www.youtube.com/watch?v=qpoxHvmWPfc> Acesso em: 26 de março de 2018
} 
No que diz respeito às questões técnicas, serão discutidos aqui o número de linhas, a velocidade, o formato, a marcação (início e final das legendas), a duração, as convenções e a posição das legendas, parâmetros característicos de qualquer tipo de legenda. Para a $\underline{L S E}^{3}$, ainda temos as informações adicionais, que são aquelas dependentes do canal auditivo, as quais, algumas vezes, precisam ser traduzidas. Essas informações estão relacionadas à tradução de efeitos sonoros e à identificação dos falantes (p.43). (grifo do autor).

Se percebe que há preocupação com estrutura e forma do texto na legenda, mas a tipografia a ser escolhida não é tratada. O motivo não é claro; pode ser devido ao desconhecimento referente ao estilo tipográfico por parte dos pesquisadores da tradução, ou por entendimento de que as fontes devam ser invisíveis ou por outros fatores. Contudo, é possível que o mergulho no campo do estilo tipográfico por tais pesquisadores venha a agregar em novos parâmetros que possam enriquecer a legendagem orientada a surdos e ensurdecidos, não especificamente para cinema, mas também em outras modalidades audiovisuais, como propagandas, games, videoclipes etc.

Especificamente sobre as características visuais dos tipos presentes nos padrões de legendagens estabelecidos no Brasil, há recomendações que caracterizam o reconhecimento de recursos sonoros e visuais específicos. Dentre eles, a identificação dos falantes, de sons de ambientação, de locuções externas, de pensamentos de personagens, trilha sonora.

No Brasil e na França são encontradas diferentes formas de identificar os recursos sonoros citados. Enquanto no país europeu, as soluções se caracterizam pela utilização de cores específicas nas legendas para cada parâmetro, em terras brasileiras se convencionou o uso de caracteres em diferentes formatos: regular, itálico, caixa-alta, caixa-baixa etc.

\section{Metodologia}

Se verificou, durante a realização de disciplina sobre Tradução Audiovisual ${ }^{4}$ que dentre as características abordadas na área sobre a legendagem de filmes para surdos e/ou ensurdecidos não estavam o aspecto formal e semântico dos estilos tipográficos. Na proposição de tal recurso acessível, a escolha tipográfica segue a recomendação de simplesmente compor os textos diegéticos e extradiegéticos, tendo que ser, portanto, "invisíveis" - no sentido de apenas possibilitar a leitura confortável e fluída do conteúdo verbal suportado na mensagem. Sendo assim, as características formais (de linguagem) do estilo tipográfico, que poderiam fazer extrapolar o universo verbal, não eram contempladas. Dessa forma, partindo-se dos pressupostos anteriormente enunciados (ver página 3 ) foram realizados ciclos de experimentos para avaliar a percepção de determinadas fontes e sua relação com imagens e personagens do universo audiovisual ocidental. Os experimentos foram realizados com diferentes respondentes, dentre ouvintes e surdos, com e sem a presença do pesquisador. A seguir, são detalhados os procedimentos.

\footnotetext{
${ }^{3}$ Legendagem para surdos e ensurdecidos.

${ }^{4}$ Ministrada no segundo semestre de 2017, na Pós-Graduação em Letras da Universidade de São Paulo.
} 


\section{Ciclo 1 - Ouvintes | Investigação do pressuposto 1 (ver página 3)}

É comum, nos dias de hoje, a utilização do estilo tipográfico como recurso informacional que extrapola o conteúdo verbal das palavras escritas. Jornais, revistas, a publicidade e, claro, o universo das marcas estão repletos de exemplos. Para os profissionais da área gráfica e de comunicação, parece óbvia a conexão entre imagens, ideias e tipografia, mas será que o público "leigo" é capaz de assimilar tais relações? Tentando buscar essa resposta, foi realizado experimento com indivíduos que não se relacionam àquele universo profissional.

\section{Experimento 1}

\section{Procedimento}

Atividade presencial com seis indivíduos, com faixa etária entre 25 e 65 anos, de diferentes formações acadêmicas (ou sem formação), e de gêneros diferentes. Uma folha ilustrada com cinco imagens ${ }^{5}$ (figura 1) foi apresentada, às quais o entrevistado deveria conectar a cinco estilos tipográficos, selecionados pelo autor deste artigo. A conexão se dava por uma linha ligando os dois campos.

\section{Escolha tipográfica}

Partiu-se, inicialmente, da seleção de imagens fotográficas, que teve como princípio a utilização de elementos contrastantes entre si, de modo que a definição dos estilos tipográficos causasse o mínimo de confusão possível dentre os respondentes. A escolha, portanto, foi baseada no contraste de ideias e em imagens que pudessem compor o repertório visual dos respondentes. Em seguida, a partir de conjunto tipográfico disponível, o autor utilizou de sua experiência com tipografia para selecionar estilos que se relacionassem às imagens elencadas. Especificamente, a relação seria:

1. Crianças brincando e fonte manuscrita, com setinhas que indicam a composição caligráfica para que está aprendendo a escrever;

2. Cangaceiros e fonte baseada na técnica da xilogravura, presente na literatura de cordel típica do nordeste brasileiro;

3. Casamento e fonte sofisticada, com arremates suaves e contraste entre traços espessos e finos;

4. Caveira tocando baixo e fonte pesada, com traços fortes e pontiagudos, que lembram a marca de bandas de Heavy Metal;

5. Estudantes e fonte robusta com serifa quadrada bem destacada, típica de do universo universitário massivamente divulgada em filmes estadunidenses.

As fontes eram diferentes, mas o texto apresentado era o mesmo: "me identifico com...", uma vez que a proposta era vestir o texto com diferentes mensagens.

\footnotetext{
${ }^{5}$ Crianças brincando, cangaceiros, casamento, caveira tocando guitarra, estudantes universitários.
} 


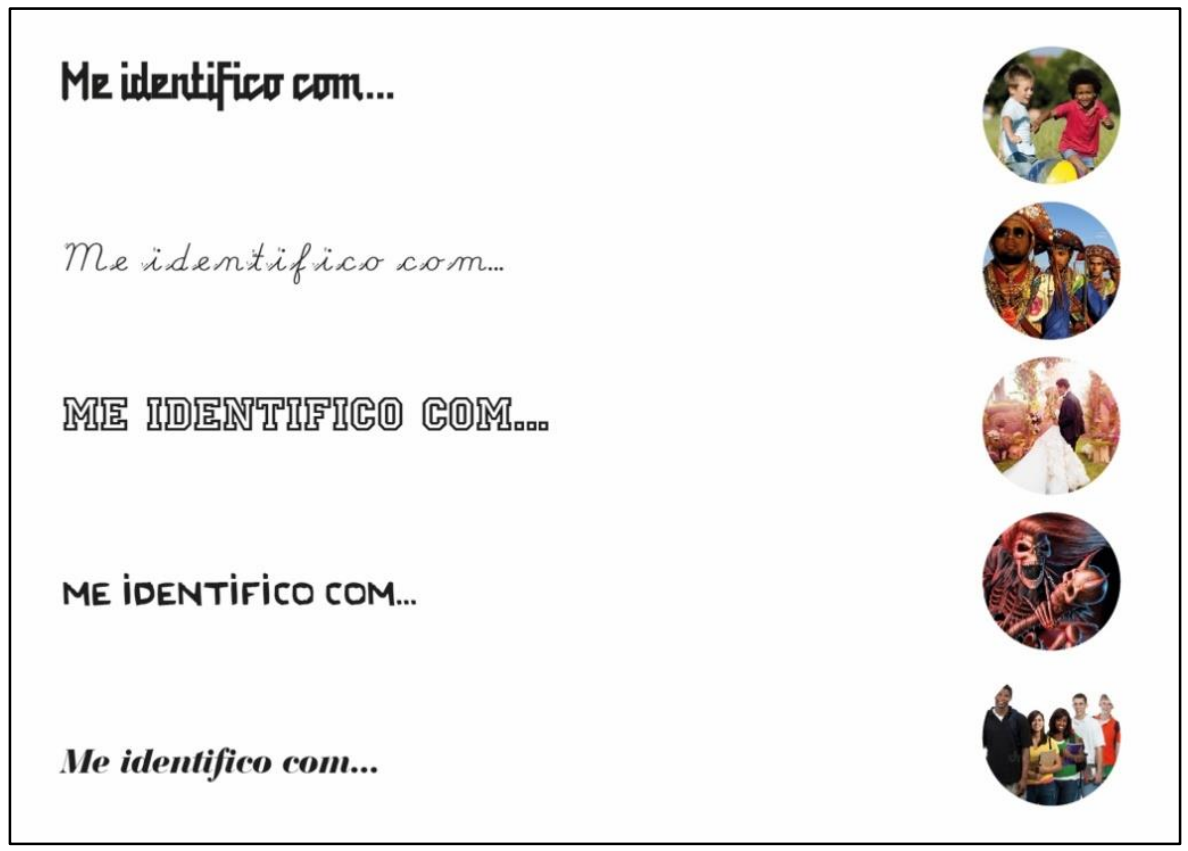

Fonte: criação do autor (2018)

\section{Experimento 2}

\section{Procedimento}

Os mesmos indivíduos, ao finalizar o experimento 1, passavam à segunda questão. Dessa vez, pontuou-se na possibilidade de trazer interpretar o imaginário de um personagem do cinema em um estilo tipográfico próprio. Nesta atividade, os respondentes deveriam, inicialmente, marcar um xis nos campos $\mathrm{S}$ (sim) ou $\mathrm{N}$ (não), para esclarecer se conheciam ou não os personagens em questão. Se imaginou que com isso, seria possível uma análise mais precisa sobre possíveis equívocos ou acertos quanto às respostas. Em seguida, o sujeito deveria preencher o quadro em branco com o número da fonte que acreditasse se relacionar ao personagem (Figura 2).

Se utilizou de folha impressa com 12 personagens conhecidos no mundo audiovisual, e da escolha minuciosa de também 12 diferentes estilos tipográficos. As fontes eram diferentes mas o texto apresentado era o mesmo: "sou a voz de".

\section{Escolha tipográfica}

Primeiro, houve a seleção dos personagens a serem ilustrados - sujeitos com diferenças entre si, de modo que a definição dos estilos tipográficos causasse o mínimo de ambiguidade possível dentre os respondentes. Em seguida, se deu a seleção tipográfica (à frente o detalhamento). Destaque-se que com a ideia "sou a voz de ..." ${ }^{6}$, não se deseja propor a ideia de que

\footnotetext{
${ }^{6}$ Como veremos detalhadamente no tópico "resultados", a ficha de avaliação foi modificada.
} 
o estilo tipográfico venha a estampar vozes de personagens específicos em conteúdo fílmico, o que, de repente, poderia ser interessante e, quem sabe, pesquisado em outro estudo. Contudo, se utilizou dessa proposta para que ficasse mais claro ao entrevistado a noção de que a fonte tem o papel de interpretar a ideia do personagem, seja pelo que representa ou pelo que o filme propõe.

Figura 2 - Fontes e personagens

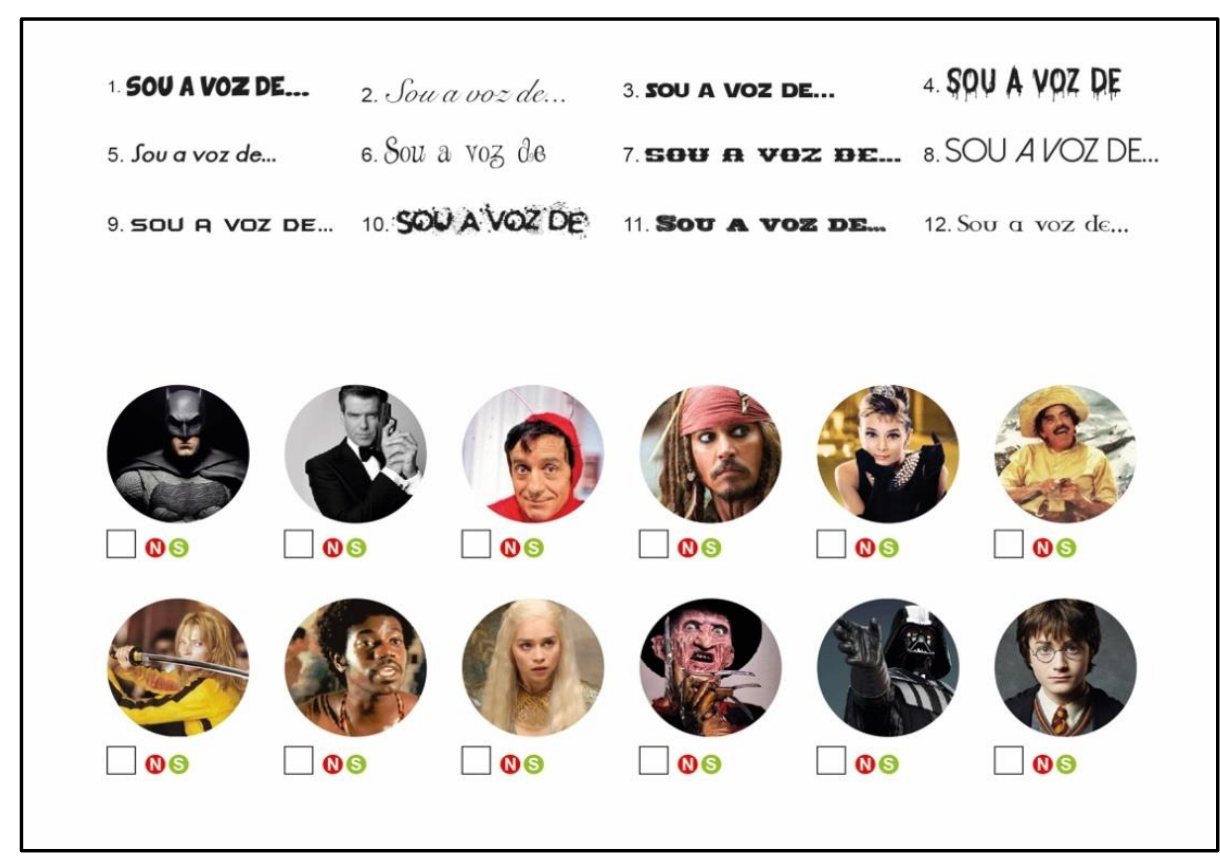

Fonte: criação do autor (2018)

\section{Ciclo 2 - Surdos | Investigação dos pressupostos 2, 3 e 4 (ver página 3)}

Durante o ciclo 1, sobretudo quando da análise dos resultados, sentiu-se a necessidade de um novo cliclo, dessa vez envolvendo pessoas surdas, a fim de avaliar os pressupostos 2,3 e 4 . 0 maior entrave nessa ideia seria o de comunicação, uma vez que o pesquisador não tem conhecimento sobre a Língua Brasileira de Sinais - LIBRAS, bem como não contava com intérpretes para tanto, o que também poderia significar um custo financeiro para a realização da pesquisa. Assim, foi realizado contato com a Associação dos Surdos da Grande Florianópolis - ASGF, por meio de sua presidenta, a quem foi apresentada a proposta de pesquisa, que prontamente foi atendida pela mesma, possibilitando, assim, a realização.

\section{Experimento 3}

\section{Procedimento}

Ao contrário do experimento realizado com pessoas ouvintes, o experimento 3 - com surdos, foi feito sem a presença do pesquisador, por meio do envio das fichas, em arquivos PDF por e-mail. A supra citada, presidenta da ASGF, imprimiu os documentos e encaminhou para surdos cadastrados na associação, que, por sua vez, responderam e devolveram as fichas, que foram digitalizadas e encaminhadas ao pesquisador, via e-mail. Com esse público, apenas o experimento 1 (de imagens e fontes) foi considerado, uma vez que durante a geração do PDF da ficha correspondente aos personagens, houve alguma falha no sistema que modificou as fontes selecionadas pelo pesquisador, portanto invalidando-as. Abaixo, a figura 3 apresenta a ficha com as fontes corretas: 
Figura 3 - Fontes e personagens

1. ME IDENTTFICO COM

2. Me identifico com

3. Me identifico com

4. ME IDENTIFICO COM

5. METDENTIFCOCOM

6. ME IDENTIFICO COM

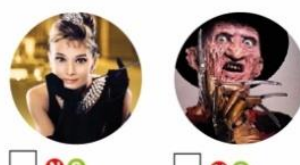

$\square$ ๑ง
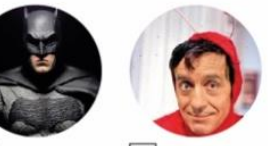

$\square \otimes \odot$

$\square \otimes \odot$

7. Me identifico com
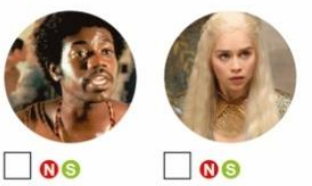

Fonte: criação do autor (2018)

\section{Escolha tipográfica}

Inicialmente, tal como se percebe na comparação entre as figuras 2 e 3, é preciso esclarecer que houve modificações quanto à ficha de respostas. Detectou-se que, o experimento 2 era muito demorado e tinha complexidade alta, haja vista a grande quantidade de personagens em análise. Da mesma forma, alguns estilos tipográficos tinham características muito semelhantes, o que contradizia o objetivo da pesquisa em causar a menor confusão possível. Assim, optou-se pela redução a 7 personagens e fontes. Outra modificação foi a utilização do mesmo texto da Ficha do primeiro experimento, "Me identifico com", uma vez que por tratar de surdos, se optou pela não utilização da ideia de "voz" (Figura 3).

1. Chapolin Colorado e fonte cômica, típica em títulos humorísticos, seja em mídia impressa ou em conteúdo audiovisual;

2. Bonequinha de luxo (Holly Golightly) e fonte luxuosa, com formas suaves, curvas vistosas e corpo delicado;

3. Harry Potter e fonte Wizard, semelhante às fontes presentes nas marcas dos filmes e livros do personagem;

4. Batman e fonte que ilustra a marca e a identidade visual do filme "Cavaleiro das Trevas";

5. Zé Pequeno e fonte poluída, que lembra pichações em muros urbanos, acrescidas de marcas de balas, uma referência à violência;

6. Freddy Krueger com fonte que faz alusão ao sangue que escorre em superfície.

7. Daenerys (Game of Thrones) e fonte inspirada em culturas antigas, no caso a Celta. 


\section{Experimento 4}

Os dados coletados com o experimento 3 foram ricos, mas o problema com a geração do PDF da ficha 2, bem como a distância presencial entre pesquisador e respondentes despertaram a necessidade de um quarto experimento, dessa vez presencialmente e com o público surdo. 0 problema de comunicação devido ao desconhecimento de LIBRAS deveria, portanto, ser contornado.

Em fevereiro de 2018, foi realizado contato com a Associação dos Surdos de São Paulo (ASSP), que realiza, pelo menos, um encontro semanal com seus associados. Dessa forma, o pesquisador se dirigiu a um destes encontros ${ }^{7}$.

No local, o pesquisador levou papel, lápis e um computador para tentar conversar e realizar o procedimento, que felizmente contou com a participação de uma intérprete que integra o grupo, facilitando e possibilitando a realização do experimento.

\section{Procedimento}

Realizado presencialmente, com a colaboração da intérprete de LIBRAS, Daniela. Foram utilizadas as fichas 1 e 2, porém houve uma mudança no conteúdo verbal: a expressão "me identifico com" foi substituída por "parece com", por sugestão da psicóloga que atendeu o pesquisador na associação de Florianópolis.

Quanto ao procedimento de preenchimento das respostas, se optou pela utilização de laptop ao invés de folhas impressas.

\section{Resultados}

Inicialmente, os experimentos do ciclo 1 foram realizados virtualmente, com o envio das fichas de avaliação via aplicativo Whatsapp. Tal processo, entretanto, se revelou falho, uma vez que as respostas apontaram possíveis ações de descuido dos respondentes. Algumas respostas apresentaram relações improváveis, tais como a conexão de fontes e imagens sem relação aparente. É preciso frisar que a seleção de fontes e imagens foi realizada pelo autor, a partir de critérios que buscassem simplificar a relação entre os componentes. Houve, contudo, a avaliação de que poderia haver alguma confusão mínima entre fontes e imagens que apresentassem características semelhantes, tais como se identificou nas relativas a casamento e a crianças brincando, bem como na dos cangaceiros e da caveira heavy metal. Todavia, se considera que dificilmente haveria conexão entre determinados estilos tipográficos, tais como crianças e heavy metal. Entretanto, um dos respondentes (o quarto a ser abordado) conectou tal fonte à imagem das crianças, o que despertou a necessidade de aprimorar o processo de coleta de dados, a partir do acompanhamento presencial na execução da atividade, seguido de questionamentos sobre os motivos que levaram os respondentes às suas escolhas, sem, contudo, interferir nas respostas. Assim, as primeiras interações (online) foram desconsideradas na pesquisa e novos respondentes foram buscados.

\footnotetext{
${ }^{7}$ Realizado na Escola Municipal de Educação Bilíngue para Surdos Helen Keller, na capital paulista (bairro Aclimação).
} 
Sobre o experimento 2, é preciso esclarecer que também houve modificações quanto ao método de coleta de dados. Detectou-se que na proposta inicial que o número de 12 personagens tomava muito tempo, além de agregar carga de complexidade desnecessária à atividade - tal como já esclarecido no item "metodologia".

Como resultados, se pode afirmar que os experimentos relacionados à conexão entre estilo tipográfico e imagens, representados na Figura 1, foram os que obtiveram maiores níveis de convergência entre as relações propostas pelo pesquisador e as percebidas pelos respondentes. Tanto surdos quanto ouvintes tiveram bons níveis de correspondência nesta atividade, o que pode fortalecer o pressuposto 3 (ver página 3). Apenas estilos tipográficos com características formais semelhantes (cangaceiros/heavy metal; casamento/crianças) causaram, entre si, confusão por parte dos respondentes em todos os ciclos, independente da característica auditiva do respondente.

O experimento 2 também revelou congruência entre proposta do pesquisador e respostas. Se imaginava que o desconhecimento de alguns personagens por parte de respondentes - o que se verificou em alguns casos - poderia causar desvios importantes nas respostas. Personagens como Chapolin Colorado e Freddy Krueger, entretanto, tiveram seus estilos tipográficos identificados sem maiores problemas, inclusive por respondentes que não demonstraram segurança quanto ao conhecimento do personagem (no caso do protagonista de terror). Sobre essa questão, fato curioso foi a identificação, no experimento 4, da personagem do filme "Bonequinha de Luxo" e sua fonte correspondente. Mesmo os entrevistados que afirmaram desconhecer a personagem, conseguiram relacioná-la à fonte proposta. O mesmo ocorreu com o personagem Freddy Krugger. A partir dessa observação, é possível imaginar que os pressupostos 1, 2 e 3 podem ser verificados nesta situação, uma vez que o estilo tipográfico foi o único recurso oferecido aos respondentes para realizar a relação com a imagem.

O experimento 3, como já citado, teve excelente aproveitamento quanto à ficha 1 de resposta (imagem/fonte). Quanto à folha 2 (personagem/fonte), se resolveu desconsiderar tais respostas, haja vista que os respondentes não indicaram no cartão se conheciam ou não os personagens; houve um imprevisto na impressão do material, o que acarretou na repetição de duas fontes; além do quê a não interação entre pesquisador e respondentes da atividade impossibilitou uma avaliação mais exata das respostas, uma vez que foi considerado a ocorrência de alguns desvios incompatíveis, tais como o personagem Zé Pequeno com a fonte humorística (pensada, inicialmente para o Chapolin).

No geral, podemos afirmar que os resultados atenderam a expectativa de que o estilo tipográfico pode carregar consigo uma mensagem que vai além do texto que a tipografia suporta, apesar do pressuposto 4 - que seria o mais robusto para caracterizar tal possibilidade - não ter sido validado (nem refutado) declarativamente.

Merece destacar aqui, que em uma possível ampliação futura deste tipo de experimento, há a necessidade de caracterização mais detalhada dos grupos de respondentes (surdos ou não), tendo em vista que se deve considerar as diversidades cultural, de formação e de características sociais e regionais (a saber, alguns dos respondentes surdos paulistas não reconheceram a tipografia alusiva à Literatura de Cordel, típica do nordeste brasileiro) visando obter resultados os mais fidedignos e representativos possíveis. 


\section{Considerações Finais}

Este artigo surgiu de inquietação a partir dos processos de pesquisa e proposições de tradução oriundas do campo dos Estudos da Tradução Audiovisual. Tal inquietude foi fruto da percepção de que havia uma lacuna nas considerações abraçadas por aquele campo, tendo em vista que o universo tipográfico, naquela área, se resumia às suas características de leitura, sendo analisado como um coadjuvante ao serviço da mensagem verbal. Deste modo, se buscou ampliar as potencialidades da tipografia, buscando, em suas formas (e linguagem), contextualizar o conteúdo verbal ao campo semântico proposto pelas fontes. Sugerimos que tal modo de exploração tipográfica poderia contribuir com a amplificação da imersão do público surdo ao conteúdo audiovisual dos filmes, uma vez que foi percebida que as fontes, quando selecionadas adequadamente ou compostas com fins de comunicação por meio da forma (e linguagem), pode ter capacidade de transmitir informações que vão além da mensagem verbal que suportam. Considera-se que os dados levantados foram insuficientes para legitimar com vigor os pressupostos colocados, sobretudo o de número 4. Poderia ser mais efetiva, a utilização de vídeos (procedimento habitual no campo das pesquisas em Tradução Audiovisual Acessível) para confirmar, por exemplo, a validade do mesmo. Entretanto, acreditamos que a temática em questão demonstrou potencial para investigações mais aprofundadas a partir de subtemas específicos, tais como a publicidade, donde já se verifica abundante utilização do estilo tipográfico como recurso semântico; bem como no universo dos videogames; além da programação televisiva e das redes sociais com foco na exibição audiovisual - tal como o Youtube, o que poderia ampliar o potencial comunicativo através da legendagem, dentro do contexto da acessibilidade para todos (incluindo os surdos), como uma contribuição do Design por meio da linguagem tipográfica e de suas características.

Julgamos, por fim, que este tema de pesquisa pode e deve ser aprofundado por aqueles que se debruçam sobre o campo da Tradução Audiovisual, sobretudo por meio de pesquisas interdisciplinares e que tenham a participação de pessoas surdas. No campo do Design Gráfico e da Tipografia, há conteúdo suficiente para justificar a escolha de estilos tipográficos na proposição de mensagens visuais capazes de atender aos objetivos de ampliar a imersão e contribuir com a inclusão daquele público.

\section{Referências}

ARAÚJO, V. L. S.; ALVES, S. F. (Org.) ; MAUCH, C. (Org.) ; NEVES, S. B. (Org.) . Guia para Produções Audiovisuais Acessíveis. 1. ed. Brasília: Ministério da Cultura/Secretaria do Audiovisual, 2016. v. 1. $1 \mathrm{p}$.

ARAÚJO, V. L. S.; NASCIMENTO, A. K. P. . INVESTIGANDO PARÂMETROS DE LEGENDAS PARA SURDOS E ENSURDECIDOS NO BRASIL. Tradução em Revista (Online), v. 2, p. 1-18, 2011.

BRINGURST, Robert 2005. Elementos do estilo tipográfico. São Paulo: Cosac Naity.

BAINES, Phill; HASTAM, Andrew. Type \& typography. 2nd ed. London: Laurence King, 2005.

FARIAS, L. Priscila. Estudos sobre tipografia: letras, memória gráfica e paisagens tipográficas. 2016. 216 f. Tese (Livre-docência) - Faculdade de Arquitetura e Urbanismo, Universidade de São Paulo, São Paulo, 2016.

FRUTIGER, Adrian. El libro de la tipografía. Barcelona: GG Diseño, 2007. 
JUÁREZ, Dalia. Introducción a la Tipografía. Acesso em <22.dez.2017> Disponível em http://www.astraph.com/udl/biblioteca/antologias/intoduccion_tipografia.pdf

LUPTON, Ellen. Pensar com tipos. São Paulo: CosacNaify, 2006.

Tipos na tela. São Paulo: Gustavo Gilli, 2015.

NASCIMENTO, A. K. P.; TAGNIN, S. E. O. A música e os ruídos na legendagem francesa para surdos e ensurdecidos. Letras \& Letras (Online), v. 30, p. 214-243, 2014.

Pinheiro, M. ; (2012) Tipografia Inclusiva e Legibilidade. Convergências - Revista de Investigação e Ensino das Artes, VOL V (10) Retrieved from journal URL: http://convergencias.ipcb.pt

YOUTUBE. Batman (1966): Fight Scenes-Season 3 (Pt.2). Disponível em: <https://www.youtube.com/watch?v=qpoxHvmWPfc> Acesso em: 26 de março de 2018

\section{Agradecimentos}

Agradecemos à Fundação de Amparo à Pesquisa do Estado de São Paulo (FAPESP) pelo apoio e financiamento a essa pesquisa, realizado por meio do protocolo $2017 / 13180-8^{8}$.

8 "As opiniões, hipóteses e conclusões ou recomendações expressas neste material são de responsabilidade do(s) autor(es) e não necessariamente refletem a visão da FAPESP" 